\title{
Validation of effectiveness of sterilization for different weighted surgical instrument packages and their impacts on operators.
}

\author{
Huang Hao, Zhou Xiao-li*, Chenbo Qiao, Zheng Shu Wen, Wu Xiao Na, Yang Jing Jing \\ Central Sterile Supply Center of West China Hospital, Sichuan University, Sichuan Province, PR China
}

\begin{abstract}
Objective: To investigate the effectiveness of sterilization of different weighty surgical instrument packages and their effect on packing experience such as operators' working satisfaction and acceptance. Methods: Orthopedic surgical instruments of the same material were grouped into 8 different weight groups: $7 \mathrm{~kg}, 9 \mathrm{~kg}, 11 \mathrm{~kg}, 13 \mathrm{~kg}, 15 \mathrm{~kg}, 17 \mathrm{~kg}, 19 \mathrm{~kg}, 21 \mathrm{~kg}$. Class 4 multi-variable CI, Class 5 integrating indicator and biological indicators were put at the least favorable position for sterilization within the packages and the monitoring results were interpreted after normal sterilization cycle to assess the sterilization performance. The operators packed the instrument with the same packaging materials, and then investigators evaluated the acceptability of the instrument package weights to the operators.

Results: Instrument packages weighing between $7 \mathrm{~kg}$ and $11 \mathrm{~kg}$ produced acceptable results in chemical and biological monitoring using the normal sterilization procedure. Package weight exceeding $11 \mathrm{~kg}$ indicated uneven color change in Class 4 multi-variable CI, while Class 5 integrating indicator and biological monitoring produced acceptable results only with some wet packs. Instrument packages exceeding $11 \mathrm{~kg}$ made packing difficult for operators and resulted in low satisfaction.

Conclusion: Package weights not exceeding $11 \mathrm{~kg}$ were associated with effective sterilization in normal sterilization procedures, and with good operator satisfaction.
\end{abstract}

Keywords: Weighty orthopedic surgical instruments, Sterilization effectiveness, Packaging operation experience. Accepted on May 22, 2017

\section{Introduction}

Medical equipment have gradually developed into complex and high-tech instruments with the rapid development of medical technology. Orthopedic surgery equipment such as those used for joint replacement and internal fixation, are weighty, high-risk machines due to combination of multiple instruments, heaviness and varied shapes. The heaviest instrument set may weigh up to $21 \mathrm{~kg}$. According to Chapter 5.7.6 of Healthcare Standard WS 310.2-2009 promulgated by Chinese Ministry of Health, the weight of instrument pack under steam sterilization should not exceed $7 \mathrm{~kg}$, while dressing package should not exceed $5 \mathrm{~kg}$ [1]. However, instrument set for surgery cannot be split into smaller units. Complications arising from implants have increased over the years [2]. These implant complications are associated with hospital infection due to exogenous bacteria contamination arising from instrument sterilization defects [3].

The present study was aimed at investigating the effectiveness of sterilization of different heavy surgical instrument packages $(7-21 \mathrm{~kg})$, and the acceptability of the packages to the operators. This was with a view to ensuring high quality of sterilization so as to control hospital infection and decrease operator dissatisfaction.

\section{Materials and Methods}

\section{Materials}

Orthopedic surgical instruments of same material (periosteal stripping, bone knives, bone hammer, rongeur, holding bone and marrow filing) were grouped into eight categories: $7 \mathrm{~kg}, 9$ $\mathrm{kg}, 11 \mathrm{~kg}, 13 \mathrm{~kg}, 15 \mathrm{~kg}, 17 \mathrm{~kg}, 19 \mathrm{~kg}, 21 \mathrm{~kg}$ (numbered 1 to 8 , with only one instrument set in each group. Class 4 multivariable CI, Class 5 integrating indicator and biological indicators were used as monitoring indicators in the sterilization process with MST 9-6-18HS2 steam sterilizer. The study recruited 15 male operators of age range 30 50 years, mean height of $175 \pm 5 \mathrm{~cm}$ and mean weight of $70 \pm 5 \mathrm{~kg}$. Fifteen female operators of age range 30 50, mean height is $160 \pm 3 \mathrm{~cm}$, and mean weight of $50 \pm 5 \mathrm{~kg}$ were also recruited.

\section{Sterilization monitoring}

The monitoring indicators were put at the three positions least accessible to steam penetration in the package, i.e. diagonal points and geometric center of pack [4]. One Class 4 multivariable $\mathrm{CI}$, one Class 5 integrating indicator and one biological indicator were put on every single point. 
The operators chose normal sterilization cycle, which was for 4 min at $134^{\circ} \mathrm{C}, 205.8 \mathrm{Kpa}$, and drying time of $15 \mathrm{~min}$. The eight groups were processed under the same conditions three times. The results were observed after cooling for $30 \mathrm{~min}$. All results were interpreted by physical monitoring, chemical monitoring and biological monitoring after the sterilization process.

\section{Survey of operators' working satisfaction}

The 30 operators used the same medical nonwoven size $100 * 100 \mathrm{~cm}$ to pack the 8 different groups of instruments. The operators scored based on comfortability and complexity. The operators' working satisfaction with packaging instruments was divided into five grades, with the indicated scores: very satisfied (5 points), satisfied (4 points), less satisfied (3 points), unsatisfied ( 2 points), and very unsatisfied ( 1 point) [5-7]. The degree of satisfaction was calculated according to statistical score in each group out of a maximum score 150 . The formula used was:
Degree of satisfaction $=($ actual score by each group $/ 150 \times$ $100) \%$.

\section{Results}

\section{Evaluation of sterilization effect}

All the eight BIs gave negative results. Class 5 integrating indicators provided acceptable result. Class 4 multi-variable CIs indicated unacceptable result in groups 4, 6, 7 and 8 . The appearance of the instrument basket indicated that groups 1 4 $(7 \sim 13 \mathrm{~kg})$ was completely dry, group $5(15 \mathrm{~kg})$ was a little humidified at the right corner of the pack; group $6(17 \mathrm{~kg})$ was wet at right corner of the pack, while group $7(19 \mathrm{~kg})$ and group $8(21 \mathrm{~kg})$ contained water drops at center of bone hammers. There were wet packs in groups weighing more than $13 \mathrm{~kg}$. These results are summarized in Table 1.

Table 1. Appearance of instruments and interpretation of sterilization.

\begin{tabular}{|c|c|c|c|c|c|c|c|c|}
\hline & Group 1 & Group 2 & Group 3 & Group 4 & Group 5 & Group 6 & Group 7 & Group 8 \\
\hline Class $4 \mathrm{Cl}$ & - & - & - & + & - & + & + & + \\
\hline Class $5 \mathrm{Cl}$ & - & - & - & - & - & - & - & - \\
\hline $\mathrm{BI}$ result & - & - & - & - & - & - & - & - \\
\hline Instruments & - & - & - & - & + & + & + & + \\
\hline
\end{tabular}

Qualified (-); failure (+)

\section{Survey of satisfaction}

The packing operating experience was assessed in terms of operator satisfaction. Operators had different degrees of acceptances to weight, but they had the same trend of satisfaction. However, the satisfaction of operators sharply declined with increasing weight of the instrument packs, both of which were negatively correlated (Tables 2 and 3).

Table 2. Statistics of operator satisfaction with different instruments weights.

\begin{tabular}{lllllll}
\hline $\begin{array}{l}\text { Experimenta } \\
\text { I group }(\mathrm{kg})\end{array}$ & Score 5 & Score 4 & Score 3 & Score 2 & Score 1 & $\begin{array}{l}\text { Total } \\
\text { Score }\end{array}$ \\
\hline No.1 $(7 \mathrm{~kg})$ & 24 & 6 & - & - & - & 144 \\
\hline No.2 $(9 \mathrm{~kg})$ & 18 & 12 & - & - & - & 138 \\
\hline No.3 $(11 \mathrm{~kg})$ & - & 22 & 8 & - & - & 112 \\
\hline No.4 $(13 \mathrm{~kg})$ & - & - & 15 & 12 & 3 & 72 \\
\hline No.5 $(15 \mathrm{~kg})$ & - & - & - & 24 & 6 & 52 \\
\hline No.6 $(17 \mathrm{~kg})$ & - & - & - & 1 & 29 & 31 \\
\hline No.7 $(19 \mathrm{~kg})$ & - & - & - & - & 30 & 30 \\
\hline No.8 $(21 \mathrm{~kg})$ & - & - & - & - & 30 & 30 \\
\hline
\end{tabular}

Table 3. Operator satisfaction with different weights.

\begin{tabular}{llll}
\hline $\begin{array}{l}\text { Experimental } \\
\text { group }(\mathrm{kg})\end{array}$ & Total score (30) & Average Score & $\begin{array}{l}\text { Degree of } \\
\text { satisfaction (\%) }\end{array}$ \\
\hline $1(7 \mathrm{~kg})$ & 144 & 4.8 & 96 \\
\hline $2(9 \mathrm{~kg})$ & 138 & 4.6 & 92 \\
\hline $3(11 \mathrm{~kg})$ & 112 & 3.73 & 75 \\
\hline $4(13 \mathrm{~kg})$ & 72 & 2.4 & 48 \\
\hline $5(15 \mathrm{~kg})$ & 52 & 1.73 & 35 \\
\hline $6(17 \mathrm{~kg})$ & 31 & 1.03 & 20.7 \\
\hline $7(19 \mathrm{~kg})$ & 30 & 1 & 20 \\
\hline $8(21 \mathrm{~kg})$ & 30 & 1 & 20 \\
\hline
\end{tabular}

\section{Discussion}

Studies have revealed steady annual increases in cases of complications in orthopedic implants due to implant-related instrument contamination as a result of defective sterilization which led to exposure to exogenous bacteria. The packing of orthopedic instruments and sterilization should strictly follow the manufacturer's written recommendations under experimental validation. If it cannot be provided by the instrument vendor, CSSD should verify the sterilization effectiveness of the instruments or split the packs and establish a scientific packaging operation and process in order to ensure 
effective sterilization quality. The heaviest orthopedic instrument set weighed about $21 \mathrm{~kg}$. Therefore, the instruments were divided into 8 groups within the range of $7 \sim 21 \mathrm{~kg}$.

In the experiment, physical monitoring, chemical monitoring and biological monitoring were applied to assess the effectiveness of sterilization. The Class 4 multi-variable CIs reacted to the key variables such as saturated steam, sterilization temperature and time by color change of dye strip or block. It was cheap and easy to use. Class 5 integrating indicator identified the sterilization effectiveness by movements in the position of a color bar. It was also easy to use, but more precise than Class 4 multi-variable CI, and equivalent in performance to biological indicator. The waterproof design was also very suitable for packaging many instruments [8]. The chemical indicators just responded to the sterilization process-related variables. Biological indicators containing spores could provide specific resistance to effective sterilization. Thus, multiple methods should be used in sterilization monitoring. Besides, the positions of indicators could affect the effect of monitoring. For baskets, chemical indicators should be placed in the geometric center of the pack. For rigid containers surrounded by inside dead corner structure, chemical indicators should be placed in the diagonal corner of the pack. Therefore, the indicators were placed as 1.2.1.1 mentioned in packages to ensure accurate and reliable monitoring results.

The results showed acceptable biological monitoring and Class 5 chemical monitoring in the sterilization of the different weight categories of instruments. However, in groups 4, 6, 7 and 8 there was one unacceptable Class 4 chemical monitoring result. The reason for this failure was most likely due to fact that the orthopedic surgical instruments were too big, overweight and hard to split into smaller units. This resulted in blockage of penetration of saturated steam. The indicator was attached on the metal surface because water condensed easily there. Due to the effect of the condensed water, the color of the chemical indicator turned to light white or silver, instead of black, which made the result inaccurate. Instrument packages cannot be used if physical monitoring, chemical monitoring or biological monitoring fails [9]. Packages should not be used if they contain wet packs or if chemical indicators fail. In this study, the instruments in basket were observed for $30 \mathrm{~min}$ at the end of sterilization. Groups 1 4 were completely dry, group 5 was a little humidified at right corner of the pack, group 6 was wet at right corner of the pack, while groups 7 and 8 contained water droplets at the center of bone hammers. It was concluded that effective sterilization could be ensured under normal sterilization cycle, i.e. for $4 \mathrm{~min}$ at $134^{\circ} \mathrm{C}, 205.8 \mathrm{Kpa}$ and drying time of $15 \mathrm{~min}$. Moreover, the weight of instrument packages should be less than $11 \mathrm{~kg}$.

In this study, 30 operators was selected by age, height, and weight to reduce the affect of these factors on the result of the experiment. Statistics of satisfaction evaluated from the 30 operators showed that most operators accepted packages weighing less than $11 \mathrm{~kg}$. If the weight exceeded $11 \mathrm{~kg}$, the operator experienced pain in the shoulder, elbow and finger, and the packaging integrity decreased significantly, which may result in low efficiency.

\section{Conclusion}

Sterilization quality control of different instrument weight packages is the major objective of sterilization work, and an issue that will continue to attract research attention. It is important to strengthen quality control with respect to cleaning, packaging, sterilization and drying, especially in the sterilization of heavy and oversized instrument packages which play vital roles in professional development. The present study revealed that effective sterilization can be ensured and the operators satisfied under normal sterilization cycle i.e. for 4 min at $134^{\circ} \mathrm{C}, 205.8 \mathrm{Kpa}$ and drying time of $15 \mathrm{~min}$. In addition, the weight of instrument packages should be less than $11 \mathrm{~kg}$. For instruments exceeding $11 \mathrm{~kg}$, it was suggested that manufacturer's written recommendations for use should be strictly followed to validate sterilization, otherwise the instrument package should be split.

\section{References}

1. People's Republic of China Healthcare Standards, WS 310.2-2009. People's Republic of China Ministry of Health, Beijing, China, 2009.

2. Dong Y. Discussion of strengthening orthopedic implantable device adverse event monitoring in medical institutions. Chinese J Pharmacovigil 2009; 11: 680-681.

3. Qiao-Xian F. Prevention and management of orthopedic implant infection in operating room. Chinese J Nosocomiol 2009; 19: 1251.

4. Xiu-ling Z, Yan-hong G. Management and technology in central sterile supply department, Beijing, Pecking Union Medical College Press, 2006.

5. Hui-ping Y, Xiaoqiang S, Xiang Y. Development of hospital discharged patients' satisfaction assessment tool. Chinese Hospital Management 2011; 31: 72-73.

6. Hai-yan W. Analysis on the effects of elderly patients with hypertension through humanity nursing. Med Innovat China 2013; 10: 067-069.

7. Si-heng Z, Yun-fei Y. Foreign student satisfaction scale reliability and construct validity test. Chinese J Health Stat 2014; 31: 686-689.

8. International Organization of Standardization, ISO 11140-1, Sterilization of health care products-Chemical indicators-Part 1: General requirements. International Organization of Standardization, 2007.

9. Yu-cun L, Ming-hui L. Training course of hospital central sterile supply, Beijing, People's Military Medical Press, 2013.

\section{${ }^{*}$ Correspondence to}

Zhou Xiao-li

Central Sterile Supply Center of West China Hospital

Sichuan University

PR China 